\title{
OTIMIZAÇÃO DOS PARÂMETROS DE REVENIMENTO DO AÇO SAE $9254^{\star}$
}

Eduardo Viedo Moreira ${ }^{1}$ Afonso Reguly²

\section{Resumo}

Analisou-se o tratamento térmico de revenimento de grampos ferroviários, modelo E2039AV, feitos a partir de barras redondas com aproximadamente $20 \mathrm{~mm}$ de diâmetro do aço SAE 9254 tendo como objetivo reduzir o tempo do processo de fabricação. A temperatura do forno foi mantida em $490^{\circ} \mathrm{C}$ e 18 grampos foram imersos no sal fundido. Em grupos de 3, os grampos foram retirados em intervalos de 10 minutos, tendo o último grupo permanecido no forno por 60 minutos. Após cada retirada foram feitos os ensaios necessários para aferir a qualidade das peças: carga estática, dureza e fadiga. Após apenas 10 minutos de revenimento os grampos já resistiam ao mínimo de $1.000 \mathrm{kgf}$ sem fraturar e apresentaram medidas de dureza próximas ao limite superior de especificação, ou seja, a dureza que era aproximadamente $58 \mathrm{HRC}$ antes do revenido, atingiu valores próximos a $48 \mathrm{HRC}$. O último teste, fadiga, foi feito apenas nos grupos de grampos revenidos por 30 e 50 minutos. Pôde-se concluir que é possível reduzir o tempo de revenimento do grampo E2039AV feito de aço SAE 9254 de 60 minutos para pelo menos 50 minutos mantendo-se a qualidade dos grampos sem a necessidade de aumentar a temperatura do forno.

Palavras-chave: Tratamento térmico; Revenimento; Aço SAE 9254.

\section{OPTIMIZATION OF TEMPERING PARAMETERS OF SAE 9254 STEEL. Abstract}

The tempering heat treatment of rail clips model E2039AV was analyzed. The clips are made of round bars of approximately $20 \mathrm{~mm}$ diameter of SAE9254 steel. This study aims to reduce the time of the manufacturing process. The furnace temperature was maintained at $490{ }^{\circ} \mathrm{C}$ and 18 clips were immersed in molten salt. Three by three the clips were removed in 10-minute intervals, with the last one remaining in the oven for 60 minutes. Following every removal, static load, stiffness, and fatigue tests were made to check the quality of parts. After only 10 minutes of tempering, the clips already resisted 1,000 kgf without fracturing and exhibited stiffness levels close to the upper specification limit. In other words, the stiffness level was about $58 \mathrm{HRC}$ before tempering and after it reached values close to $48 \mathrm{HRC}$. The fatigue test was applied only to the group of clips tempered for 30 and 50 minutes. The results of the tests indicate that it is possible to reduce the tempering time of E2039AV clips made of SAE 9254 steel from 60 minutes to at least 50 minutes preserving the quality of the clips without increasing furnace temperature.

Keywords: Heat treatment; Tempering; SAE 9254 steel.

1 Engenheiro Metalúrgico, Aluno de Mestrado Acadêmico, PPGE3M, UFRGS, Porto Alegre, RS, Brasil.

2 Doutor Engenheiro Metalúrgico, Professor, PPGE3M, UFRGS, Porto Alegre, RS, Brasil. 


\section{INTRODUÇÃO}

A procura por melhores métodos de trabalho e processos de produção tornou-se mais evidente com Frederick Taylor, que com seus estudos propôs eficiência e eficácia operacional na administração industrial [1]. A partir de então as empresas tem buscado aumentar sua produtividade e principalmente reduzir os custos para aumentar o lucro. O conhecimento dos tempos de processamento em cada etapa de produção, a identificação de gargalos e etapas da linha de produção com menores capacidades produtivas auxiliam no planejamento e tomadas de decisões que implicarão em ganhos de tempo. A capacidade produtiva corresponde à quantidade máxima de peças que podem ser produzidas em uma determinada unidade produtiva em um intervalo de tempo [2]. Desta forma, uma das maneiras de reduzir o lead time de um produto implica em aumentar a capacidade produtiva de uma etapa de processamento na sua linha de produção. Exemplo disso é a revisão contínua por parte das empresas em suas linhas produtivas buscando maior eficiência. Lead time é o intervalo de tempo entre a liberação da ordem de produção até o momento que o produto esteja pronto para ser utilizado [3].

\section{MATERIAIS E MÉTODOS}

\subsection{Grampos Ferroviários Modelo E2039AV}

O grampo é produzido através da conformação mecânica a quente de uma barra redonda com aproximadamente $20 \mathrm{~mm}$ de diâmetro e $300 \mathrm{~mm}$ de comprimento do aço SAE 9254. O grupo dos aços SAE pode ser grosseiramente descritos como aqueles que contêm um total de $5 \%$ de elementos de liga, ou menos, e na maioria das vezes são aços utilizados após tratamento térmico [4]. A Figura 1 apresenta algumas das etapas do processo produtivo do grampo.
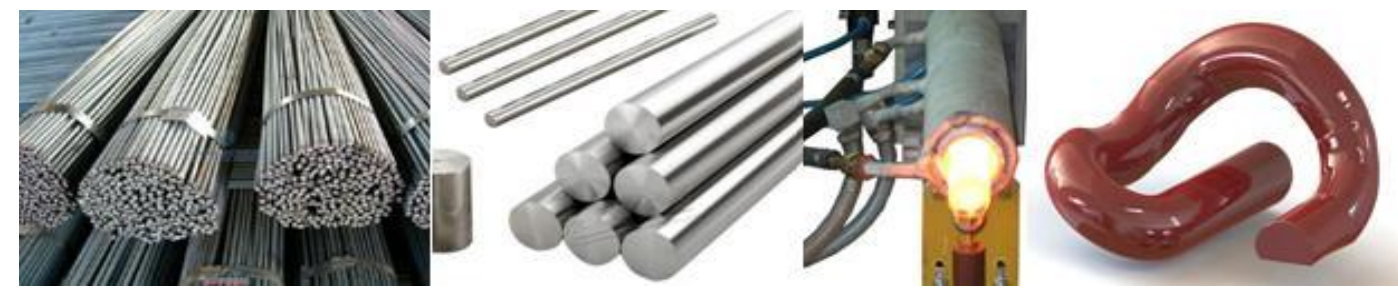

Figura 1. Amarrado de barras, barras cortadas, aquecimento da barra e grampo pronto.

\subsection{Forno de revenimento com sais fundidos}

Imediatamente após a têmpera em óleo dos grampos eles são imersos no sal fundido do forno de revenimento que opera na temperatura de $490^{\circ} \mathrm{C}$.

O revenido é o tratamento térmico aplicado aos aços endurecidos por têmpera com o objetivo de reduzir a dureza e a fragilidade da microestrutura martensítica. Uma peça que foi apenas temperada possui baixa ductilidade e tenacidade, por isso terá menor aplicabilidade devido ao risco de falha catastrófica. Nesse tratamento ocorrem mudanças na microestrutura dos aços: alguns cristais de martensita decompõem-se em ferro- $\alpha$ e cementita, o que resulta na diminuição da dureza excessiva [5]. Qualquer temperatura abaixo de $\mathrm{A}_{1}$ pode ser utilizada no revenimento de um aço, o que implica em uma ampla faixa de propriedades que pode ser atingida. Logo, esse tratamento consiste em manter o aço em uma temperatura sempre abaixo daquela alcançada para sua austenitização, por um tempo suficiente 
a obter as propriedades mecânicas desejadas [6]. Fornos que utilizam o sal de revenimento possuem boa transferência de calor, por isso a taxa de aquecimento entre núcleo e superfície é uniforme ao longo da seção transversal da peça em revenimento. Uma barra com $25 \mathrm{~mm}$ (1 polegada) de diâmetro pode chegar ao equilíbrio de temperatura com o sal do banho em 4 minutos, enquanto em outros tipos de fornos esse tempo pode subir para 20 ou 30 minutos. As peças não devem conter uma grande quantidade de água antes de serem imersas no banho de sal fundido, pois o sal reage violentamente com a umidade. Todas as peças revenidas em sal devem ser limpas imediatamente após serem removidas do forno, já que o sal remanescente na superfície é higroscópico e pode causar corrosão severa. A variação de dureza após o revenimento é comum para microestruturas diferentes, mas quando a microestrutura obtida é a mesma, o controle da temperatura se torna o fator mais importante para que não tenhamos grande variação. Em geral, os fornos de banho de sais não devem apresentar uma variação maior que $+/ 3^{\circ} \mathrm{C}$ [7].

Para imersão dos grampos foram utilizadas gancheiras de aço. Em cada gancheira foram colocados 3 grampos, totalizando 6 gancheiras. Após a passagem pelo forno de revenimento os grampos são resfriados em água, assim, poderão seguir para a próxima etapa do processo produtivo, que é o jateamento por granalhas de sua superfície para remoção do sal de revenimento. Cada uma das gancheiras contendo 3 grampos foi retirada do forno em intervalos de 10 minutos, desta forma o primeiro grupo de peças permaneceu submerso no sal por 10 minutos e o último grupo por 60 minutos. A Figura 2, meramente ilustrativa, não representa o forno de revenimento como ele realmente é, mas auxilia na compreensão do processo descrito acima.
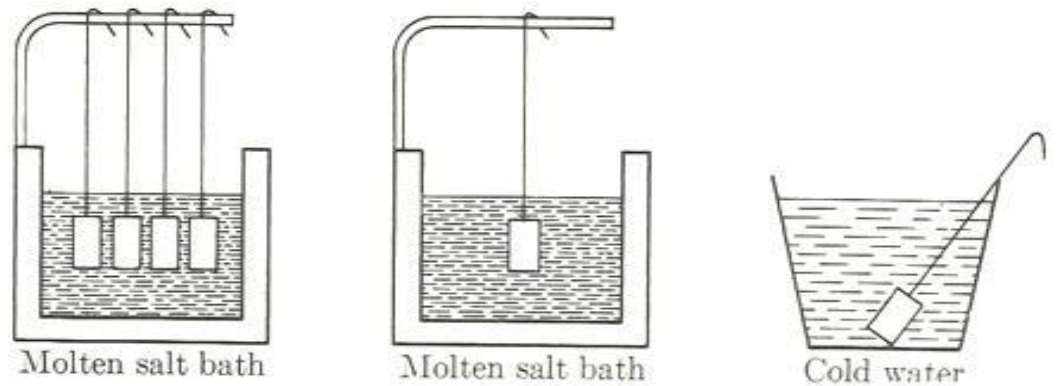

Figura 2. Desenho esquemático de um forno de revenimento em sais fundidos e tanque de resfriamento em água.

\subsection{Ensaio de carga estática}

É o primeiro ensaio para avaliar as propriedades mecânicas do grampo após o revenimento. Segundo os requisitos de qualidade deste produto, todos os grampos modelo Pandrol E2039AV, que forem revenidos, deverão suportar uma carga de tração de no mínimo 1.000 kgf sem fraturar.

A fratura consiste na separação de um corpo em duas ou mais partes em resposta à imposição de uma tensão de natureza estática (que é constante ou que varia lentamente com o tempo), em temperaturas baixas relativas à $\mathrm{T}_{\mathrm{f}}$ do material. São possíveis duas modalidades de fratura: dúctil e frágil. Essa classificação é baseada na habilidade do material em apresentar deformação plástica antes da quebra [8].

O equipamento utilizado para este ensaio é desenvolvido pela empresa matriz, a Pandrol Rail Fastenigs, localizada na Inglaterra, pois o equipamento possui características muito específicas para avaliação do produto. Na Figura 3 estão 
identificadas algumas partes da máquina utilizada no ensaio de carga estática. A aplicação da carga é feita através de um pistão que sobe em direção à peça devido ao acionamento de um pedal pneumático. Quando o relógio medidor atinge o valor mínimo determinado, o aumento da aplicação da carga é interrompido, o ar é liberado e o valor da carga suportada pelo grampo é visualizado no dispositivo localizado ao lado direito do equipamento. Todas as peças revenidas de 10 a 60 minutos foram submetidas a este ensaio.

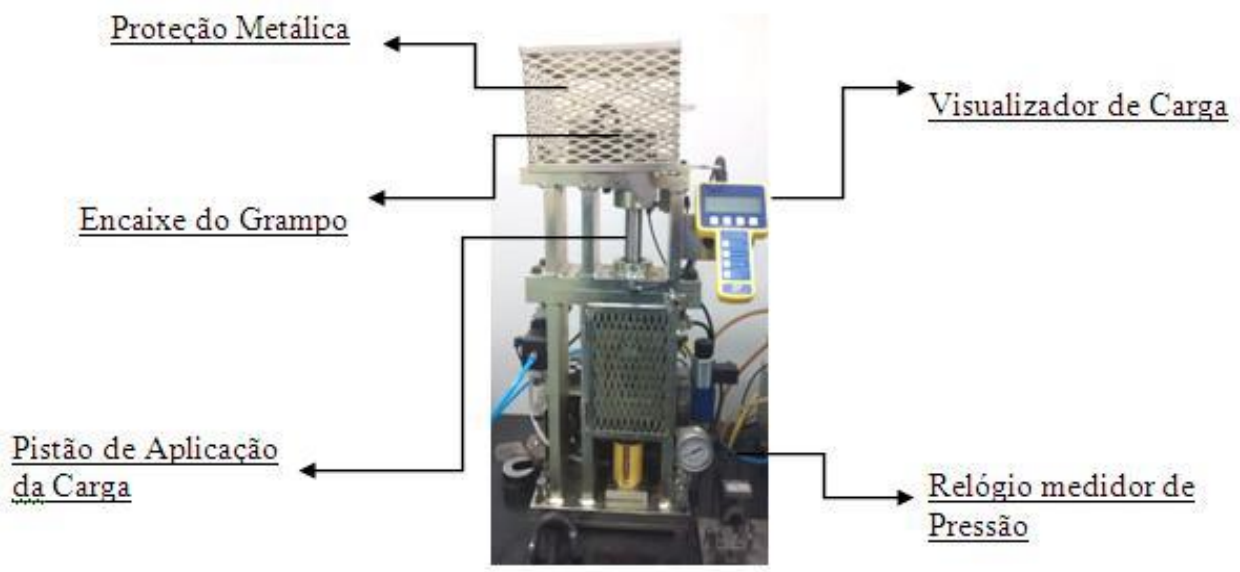

Figura 3. Máquina de ensaio de carga para grampos Pandrol E2039AV.

\subsection{Ensaio de dureza Rockwell C}

Devido à facilidade de execução, sensibilidade em detectar pequenas diferenças de durezas e ao pequeno tamanho da impressão imposta pela máquina, o ensaio de dureza Rockwell C é muito utilizado nas empresas. Após a verificação da carga estática suportada pelo grampo revenido, será necessário cortá-lo para obtenção de um corpo de prova a fim de medir sua dureza. O local normalmente escolhido para a análise da dureza da peça é a perna central do grampo. O corpo de prova obtido é retificado em ambos os lados de sua superfície e em um deles foram feitas 5 perfurações de medição da dureza Rockwell $C$, o primeiro ponto de medida no centro e os outros quatro de forma aleatória ao redor do ponto central. A localização da perna central do grampo de onde foi retirado o corpo de prova para aferição de dureza, a seção transversal do corpo de prova obtido e a máquina utilizada no ensaio estão ilustrados na Figura 4, respectivamente, da esquerda para direita. A especificação de qualidade exige um mínimo de 44 e um máximo de 48 HRC para este modelo de grampo.
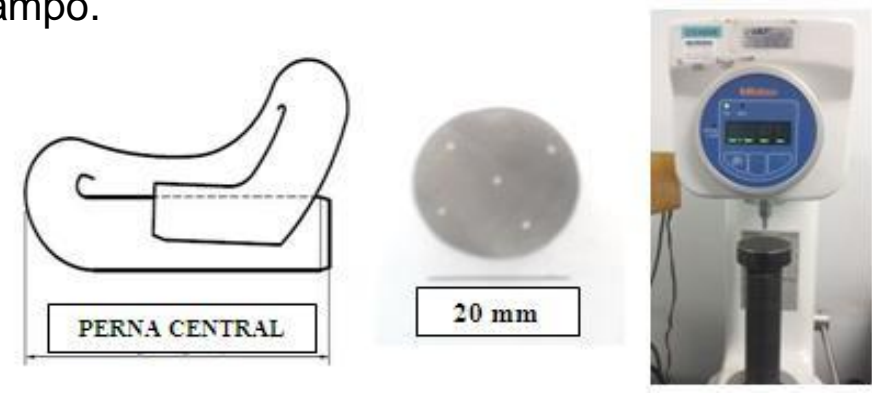

Figura 4. Vista lateral do grampo, corpo de prova da perna central e durômetro. 


\subsection{Ensaio de fadiga}

O procedimento padrão da empresa é avaliar a vida em fadiga das peças logo após o tratamento térmico de revenimento. Mesmo com resquícios do sal solidificado na superfície do grampo, ele será ensaiado na máquina de teste conforme é mostrado na Figura 5. Nessas condições, a peça deverá resistir a 3.000.000 (três milhões) de ciclos, sem fraturar, para que o lote de onde ela provém seja aprovado. Se a peça não apresentar falha, o tempo médio em teste é de 28 horas. Os grupos de grampos revenidos por 30 e 50 minutos foram submetidos a este ensaio e testados em diferentes condições de acabamento superficial. A influência do tempo de espera entre a saída do forno de revenimento e o início do teste de vida em fadiga também foi avaliado.

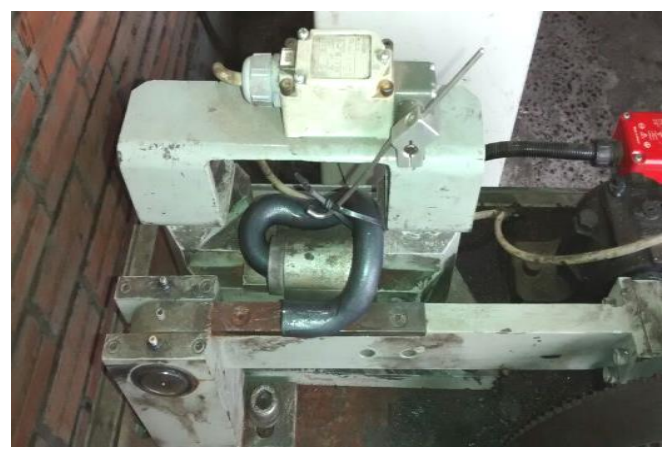

Figura 5. Máquina de ensaio de fadiga.

\section{RESULTADOS E DISCUSSÃO}

\subsection{Valores suportados de carga estática}

Os valores das cargas medidas dos 18 grampos-testes que foram retirados do forno de revenimento além de 3 grampos que foram apenas temperados (tempo zero de revenimento) estão apresentados na Tabela 1. No gráfico da Figura 6 é possível verificar que todas as peças que foram revenidas por pelo menos 10 minutos atingiram a especificação mínima de resistência ao carregamento estático de 1.000 kgf e, portanto, não quebraram. Pode-se concluir, então, que o tratamento térmico de revenimento mostrou-se eficaz em seu objetivo: reduziu a dureza e a fragilidade da microestrutura martensítica, e em apenas 10 minutos atingiu o valor de carga especificado em projeto. Os grampos que foram apenas temperados mostraram-se com baixa ductilidade e tenacidade e por isso fraturaram com menos de $1.000 \mathrm{kgf}$ aplicado.

Tabela 1. Valores de carga estática suportados por cada grampo

\begin{tabular}{lccc}
\hline Tempo & Grampo 1 & Grampo 2 & Grampo 3 \\
& & & \\
\hline 0 min & 845 & 755 & 915 \\
\hline $10 \mathrm{~min}$ & 1100 & 1105 & 1107 \\
\hline $20 \mathrm{~min}$ & 1098 & 1120 & 1109 \\
\hline $40 \mathrm{~min}$ & 1087 & 1092 & 1138 \\
\hline $50 \mathrm{~min}$ & 1094 & 1117 & 1130 \\
\hline $60 \mathrm{~min}$ & 1103 & 1080 & 1103 \\
\hline
\end{tabular}




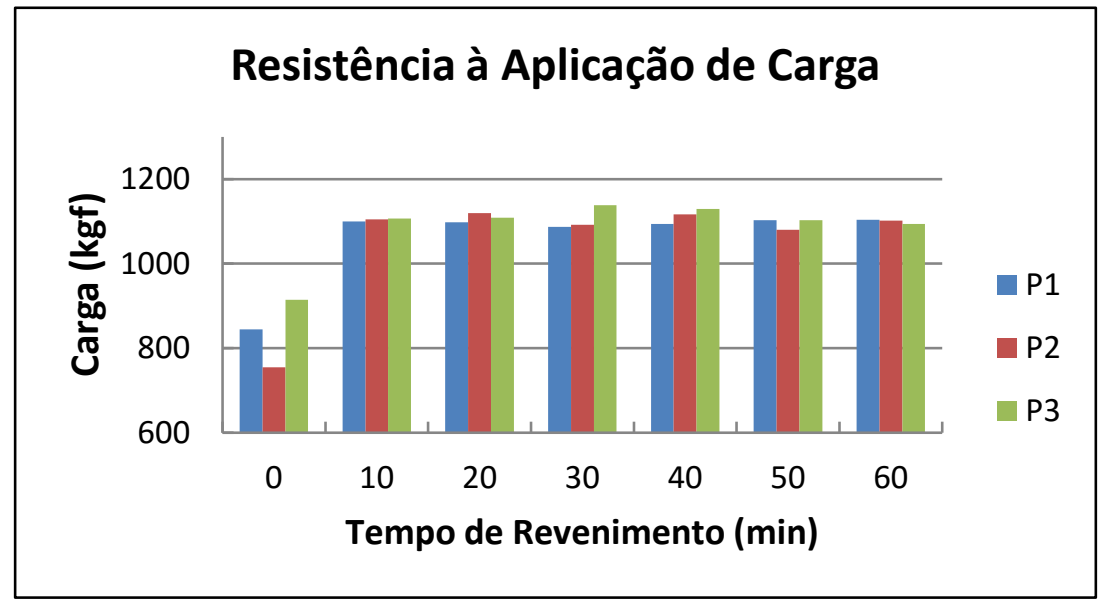

Figura 6. Carga estática $\mathrm{X}$ tempo de revenimento do grampo

\subsection{Medições de dureza Rockwell C}

A Tabela 2 apresenta os valores de dureza Rockwell C medidos em cada grampo, nos quais foram feitas 5 medidas na seção transversal da perna central. Como em cada intervalo de 10 minutos de revenimento foram retirados grupos de 3 grampos, temos 15 valores de dureza para cada intervalo de tempo.

Tabela 2. Valores de dureza Rockwell C

\begin{tabular}{lccc}
\hline Tempo & Grampo 1 & Grampo 2 & Grampo 3 \\
\hline 0 min & 59,3 & 58,8 & 54,5 \\
& 59,5 & 60,0 & 57,3 \\
& 59,4 & 60,3 & 57,6 \\
& 57,3 & 61,0 & 59,2 \\
\hline 10 min & 60,2 & 58,1 & 59,3 \\
& 47,4 & 44,2 & 46,5 \\
& 48,2 & 48,6 & 48,2 \\
& 47,8 & 47,2 & 48,3 \\
20 min & 48,2 & 47,7 & 48,8 \\
& 48,0 & 47,3 & 48,4 \\
& 43,0 & 45,2 & 43,3 \\
& 47,1 & 47,0 & 46,8 \\
& 45,2 & 47,3 & 47,2 \\
30 min & 47,2 & 47,4 & 45,9 \\
& 47,7 & 47,5 & 47,6 \\
\hline 40 min & 43,0 & 45,0 & 41,8 \\
& 46,5 & 46,4 & 46,0 \\
& 46,3 & 45,0 & 46,4 \\
& 47,6 & 47,2 & 44,5 \\
& 46,6 & 47,6 & 45,7 \\
\hline 50 min & 45,4 & 46,4 & 43,5 \\
& 47,5 & 46,9 & 47,0 \\
\hline & 47,1 & 47,2 & 46,5 \\
& 47,3 & 47,4 & 43,2 \\
& 46,8 & 47,2 & 46,6 \\
\hline
\end{tabular}




\begin{tabular}{llll}
\hline & 47,2 & 46,0 & 45,7 \\
& 45,5 & 46,2 & 46,3 \\
46,8 & 45,8 & 46,5 \\
\hline $60 \min$ & 44,0 & 44,3 & 45,8 \\
& 46,2 & 46,4 & 46,0 \\
45,4 & 46,3 & 46,7 \\
& 46,0 & 45,6 & 46,6 \\
& 46,2 & 46,7 & 46,8 \\
\hline
\end{tabular}
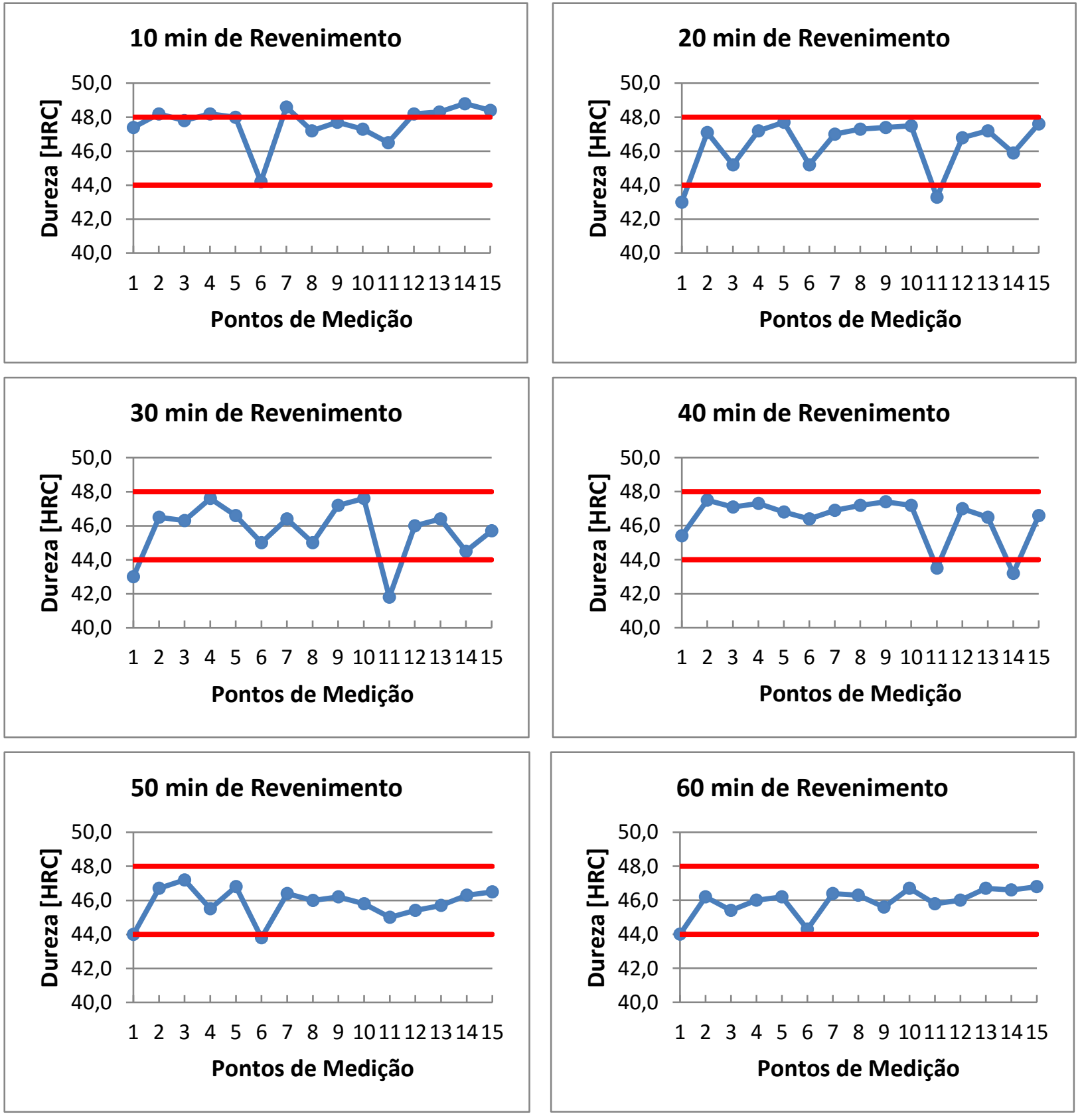

Figura 7. Valores de dureza plotados em gráficos com limites superiores e inferiores de controle 


\subsection{Resultados do ensaio de fadiga}

Tabela 3. Condições da peça antes do ensaio e resultado de fadiga

\begin{tabular}{cccc}
\hline Tempo & $\begin{array}{c}\text { Superfície do } \\
\text { Grampo }\end{array}$ & $\begin{array}{c}\text { Tempo de } \\
\text { Espera }\end{array}$ & Ciclos de carga \\
\hline $30 \mathrm{~min}$ & Com sal & Ensaio imediato & + de 3 milhões \\
\hline $30 \mathrm{~min}$ & Com sal & 5 dias & $+/-2$ milhões \\
\hline $30 \mathrm{~min}$ & Jateada & 5 dias & + de 3 milhões \\
\hline $50 \mathrm{~min}$ & Com sal & Ensaio imediato & + de 3 milhões \\
\hline $50 \mathrm{~min}$ & Com sal & 10 dias & $+/-1$ milhão \\
\hline $50 \mathrm{~min}$ & Jateada & 10 dias & + de 3 milhões \\
\hline
\end{tabular}

Os grampos revenidos por 30 minutos foram escolhidos para realizar o ensaio de fadiga porque além de terem obtido resultados dentro das especificações nos outros ensaios, caso fossem aprovados neste último, representariam uma possibilidade de redução de $50 \%$ no tempo de revenimento do produto. Já aqueles revenidos por 50 minutos foram avaliados em fadiga porque os valores de dureza estavam mais próximos ao valor nominal de especificação, assim como ocorre com os grampos revenidos em 60 minutos. Na literatura especializada é comum encontrar a afirmação que para este ensaio um fator extremamente importante é o acabamento superficial da peça que será ensaiada, por isso foram analisadas duas condições de superfícies diferentes: 1) superfície suja com sal de revenimento e 2) superfície limpa por jateamento com granalhas. Outra condição que poderia mostrar-se nociva à resistência em fadiga do grampo era o tempo que a peça aguardava para ser ensaiada. Isso porque o sal de revenimento presente na superfície do grampo pode provocar um processo de corrosão e assim gerar núcleos que dão origem à falha.

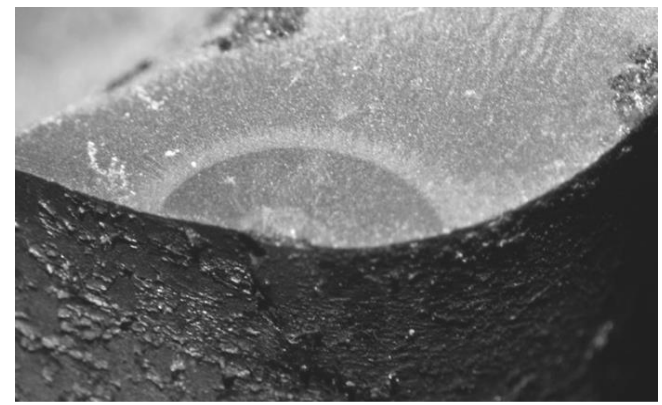

Figura 7. Falha por fadiga do grampo revenido por 30 minutos, com superfície suja pelo sal de revenimento e com 5 dias de espera para realização do ensaio.

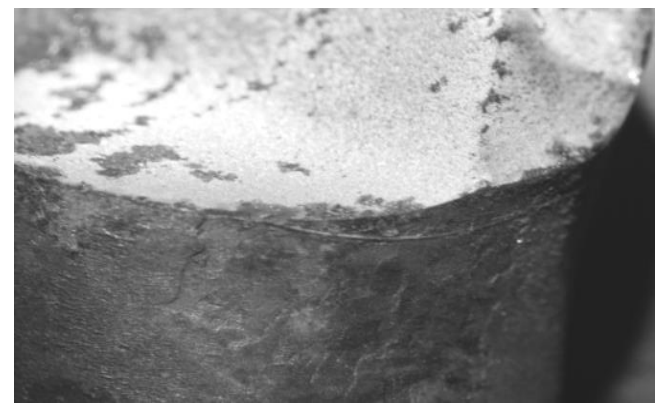

Figura 8. Falha por fadiga do grampo revenido por 50 minutos, com superfície suja pelo sal de revenimento e com 10 dias de espera para realização do ensaio. 


\section{CONCLUSÃO}

Com base nos resultados obtidos neste trabalho conclui-se que o parâmetro tempo neste processo de revenimento, para temperatura fixa de $490^{\circ} \mathrm{C}$, está superdimensionado. Tendo em vista que peças revenidas por 30 minutos foram aprovadas em todos os testes de qualidade do processo atual, que hoje opera com 60 minutos. Isso significa um ganho de $50 \%$ no tempo de processamento deste produto nessa etapa da linha de produção.

Para reproduzir os resultados deste estudo é importante lembrar que além de garantir os parâmetros utilizados no tratamento térmico de revenimento é fundamental verificar a dureza do grampo após a têmpera (etapa imediatamente anterior àquela analisada neste estudo).

O tratamento térmico de revenimento conferiu à peça melhores propriedades através da pequena modificação da microestrutura resultando em decréscimo da dureza. Pequenas variações nos valores de dureza foram encontradas em peças que permaneceram um tempo maior no forno.

Para a aprovação no ensaio de fadiga, a condição da superfície das peças mostrouse muito mais relevante que o tempo de revenido imposto a elas, pois de 30 para 50 minutos a média dos valores de dureza obtidos foi bastante próxima.

\section{REFERÊNCIAS}

1 MARTINS, P. G.; LAUGENI, F. P. Administração da Produção Ed. Saraiva, 2006.

2 MOREIRA, D. A. Administração da produção e operações São Paulo, 2009.

3 ERDMANN, R. H. Administração da produção: Planejamento, Programação e Controle. Florianópolis: Papa livro, 2007

4 GUY, A. G. Elements of physical metallurgy $2^{\mathrm{a}}$ ed Department of Metallurgical Engineering University of Florida, 1967

5 KWIETNIEWSKI, C. E. F.; KISS, F. J. Metalografia e tratamentos térmicos de aço e ferros fundidos $3^{\text {a }}$ ed. 2011 ..

6 KRAUSS, G. Steels: heat treatment and processing principles $2^{\underline{a}}$ ed. Colorado: ASM International, 1990.

$7 \quad$ ASM Handbook Vol. 4 Heat Treating ASM International Materials Park OH, 1991.

8 CALLISTER, W. D. Ciência e Engenharia de Materiais Uma Introdução $7^{a}$ ed. Editora LTC, 2008. 